\section{The Use of a Transparent Corneal Protector Permits Early Detection of Mydriasis to Prevent Blindness during Orbital Wall Fracture Surgery}

Dong-Woo Jung, Kyu Jin Chung, Yong-Ha Kim

Department of Plastic and Reconstructive Surgery, Yeungnam University College of Medicine, Daegu, Korea

Correspondence: Yong-Ha Kim

Department of Plastic and Reconstructive Surgery, Yeungnam University College of Medicine, 170 Hyeonchung-ro, Nam-gu, Daegu 705-717, Korea Tel: +82-53-620-3481, Fax: +82-53-626-0705, E-mail: yhkim@med.yu.ac.kr

This study was supported by a Yeungnam University grant in 2013.

No potential conflict of interest relevant to this article was reported.

Received: 23 May 2013 • Revised: 5 Jul 2013 • Accepted: 9 Jul 2013 pISSN: 2234-6163 • elSSN: 2234-6171

http://dx.doi.org/10.5999/aps.2013.40.6.791 • Arch Plast Surg 2013;40:791-792 Copyright (C) 2013 The Korean Society of Plastic and Reconstructive Surgeons This is an Open Access article distributed under the terms of the Creative Commons Attribution Non-Commercial License (http://creativecommons.org/licenses/by-nc/3.0) which permits unrestricted non-commercial use, distribution, and reproduction in any medium, provided the original work is properly cited.

Loss of vision has been reported in $1 \%$ of cases after treatment of a blow out fracture [1]. Postoperative blindness is one of the most serious iatrogenic complications and is due to direct injury of the optic nerve during the dissection and insertion of implant materials. In addition, intraorbital hemorrhage, vascular insufficiency, and nerve sheath injury can indirectly damage the optic nerve. When optic nerve injury occurs, high dose ( $1 \mathrm{~g} /$ day) or mega dose (30 $\mathrm{mg} / \mathrm{kg}$ loading, followed by $5.4 \mathrm{mg} / \mathrm{kg} / \mathrm{hr}$ for 24 hours) intravenous corticosteroid is recommended as a first line treatment of choice [2]. Surgical decom- pression of the optic nerve has also been recommended, but it should be performed within 24 hours and its effectiveness is not clear [3].

Papillary mydriasis occurring during the treatment of blow out fracture might indicate irreversible blindness, because it means that the ciliary ganglion or short ciliary nerves are injured [4]. The ciliary ganglion is located posterolateral to the globe, between the optic nerve and lateral rectus muscle, $1 \mathrm{~cm}$ anterior to the superior orbital fissure, and $2.9 \mathrm{~mm}$ removed from the optic nerve [5]. Near the optic nerve, the ciliary nerves run inferomedially toward the sphincter papillae muscle and with the ciliary artery above and the optic nerve beneath (Fig. 1). The short ciliary nerves and ciliary ganglion are close to the optic nerve, and mydriasis means the possibility of optic nerve damage.

Available corneal protectors are made of opaque material (Fig. 2), and therefore cannot be used to identify immediate changes in pupil size, and thus, surgeons should remove the protector and then reapply it to check the pupil size, which is time-consuming and could cause corneal laceration or abrasion. As a result, we have used the Corneal Shields (AkritiOculoplasty Logistics, Andhra Pradesh, India) transparent corneal protector (Fig. 3).

We have used the Corneal Shields protector in patients with a blow out fracture since February of 2013. Before making an incision, the size and symmetry of the pupils in the two eyes is checked, and the protector is applied immediately. When a small increase in pupil size is found during dissection, the dissection is discontinued, because of possible optic nerve injury and intravenous corticosteroid $(1,000 \mathrm{mg}$, dexamethasone) is immediately administered. The herniated soft tissue is then carefully reduced and implant materials are properly inserted. Postoperative

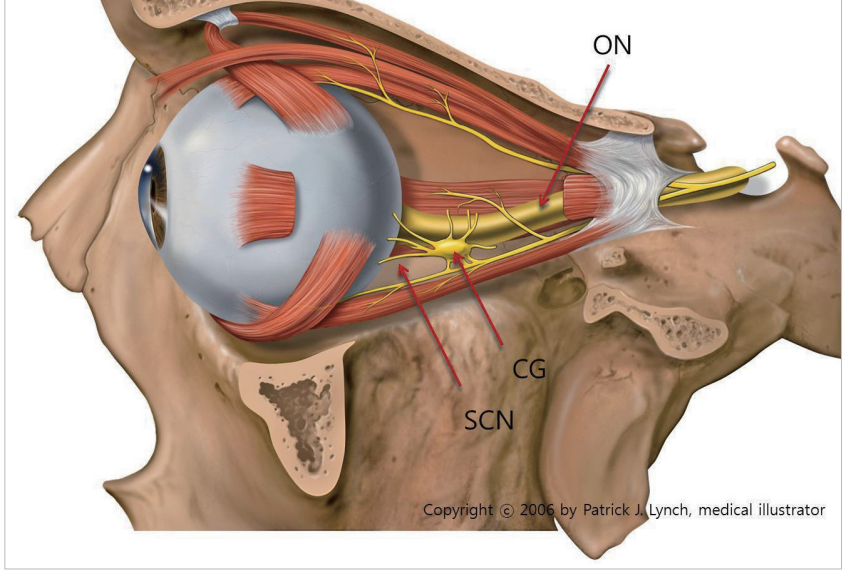

Fig. 1.

Lateral eye and anatomy with nerves (Data from Patrick J. Lynch, Medical illustrator, c2006; http:// commons.wikimedia.org/wiki/File:Lateral_orbit_ nerves_chngd.jpg). ON, optic nerve; $\mathrm{CG}_{\text {, ciliary }}$ ganglion; $\mathrm{SCN}$, short ciliary nerve. 


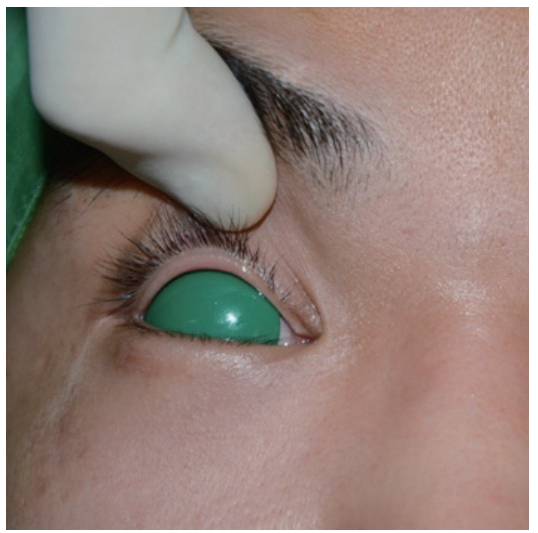

Fig. 2.

Opaque corneal protector makes the pupil invisible, and thus, it is not possible to prevent the intraoperative occurrence of mydriasis due to optic nerve injury.

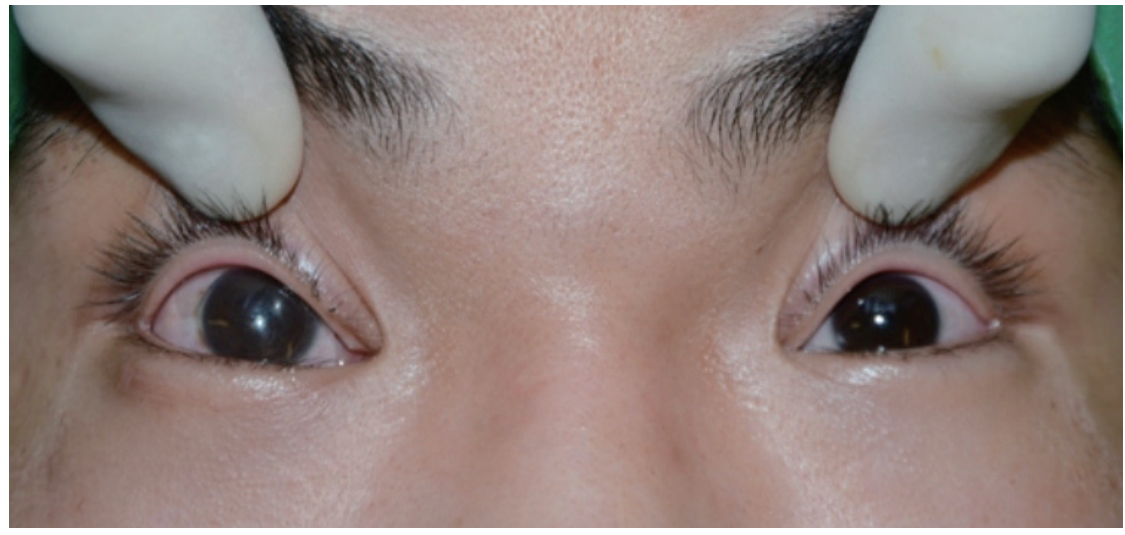

Fig. 3.

Using the transparent corneal protector (right eye), surgeons can examine changes in pupil size versus the normal eye (left eye).
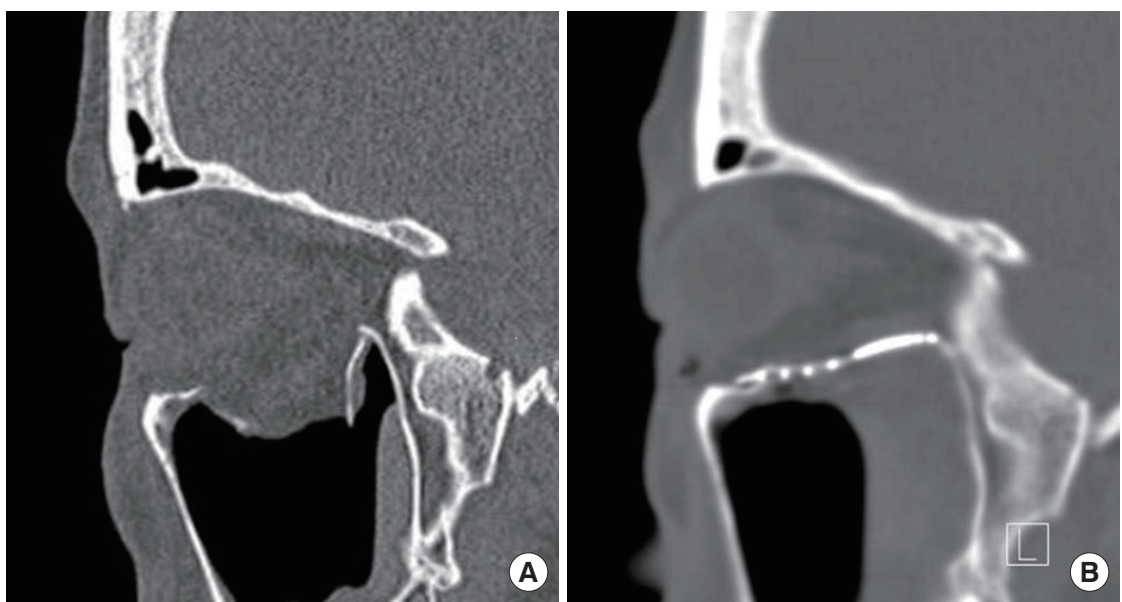

computed tomography is used to confirm that the orbital wall is well reconstructed near the optic canal (Fig. 4).

This method shortens operation times and allows possible pupil size changes to be promptly checked. Here, we introduce our method of using a transparent corneal protector to prevent the intraoperative occurrence of optic nerve injury.

\section{References}

\section{Cullen GC, Luce CM, Shannon GM. Blindness} following blowout orbital fractures. Ophthalmic Surg 1977;8:60-2.

2. Bracken MB, Shepard MJ, Collins WF, et al. A randomized, controlled trial of methylprednisolone or naloxone in the treatment of acute spinal-cord injury. Results of the Second National Acute Spinal Cord Injury Study. N Engl J Med 1990;322:1405-11.

3. Steinsapir KD, Goldberg RA, Sinha S, et al. Methylprednisolone exacerbates axonal loss following optic nerve trauma in rats. Restor Neurol Neurosci 2000;17:157-63.

4. Yeo MS, Al-Mousa R, Sundar G, et al. Mydriasis during orbital floor fracture reconstruction: a novel diagnostic and treatment algorithm. Craniomaxillofac Trauma Reconstr 2010;3:209-16.

5. Izci Y, Gonul E. The microsurgical anatomy of the ciliary ganglion and its clinical importance in orbital traumas: an anatomic study. Minim Invasive Neurosurg 2006;49:156-60. 